\title{
Entry Monitoring System
}

\author{
${ }^{1}$ Dr. P. Sivakumar, \\ Professor, \\ Dept. of Electronics and Communication Engineering, \\ Kalasalingam Academy of Research and Education, \\ Tamil Nadu-626126, India.
}

${ }^{3}$ B. Navya Sree, ${ }^{4}$ P. Mohana Varsha, ${ }^{5}$ K. Siva Varshini, Dept. of Electronics and Communication Engineering, Kalasalingam Academy of Research and Education, Tamil Nadu-626126, India.

\begin{abstract}
In many times we have encountered the entry of strangers pretending as parents, entering into college premises and creating issues. To avoid these kinds of issues, security guards and surveillance cameras alone are not enough and this cannot be controlled unless the entry of people record is computerized and details of the person are recorded. In this computerized system, software is created to enter the details and the reason for the visitor to visit. In this software, the details of the visitor will be updated in a secure manner and be stored for any future reference. If the visitors have vehicles, the vehicle details are also should be given in the request page. In this computerized method, all the details will be given in prior by the guest and will be saved securely for future reference. The entry monitoring system will import details from the administrative data processing office, the affirmed work power database as an essential inquiry table. In the end, we can know all the details about the visitors like their purpose to visit, the person they like to meet, the duration of their stay inside the campus, everything stored in our database securely in case of ant future needs.
\end{abstract}

Keywords:- Ensure Gate Safety, Entry, Gate Monitoring.

\section{INTRODUCTION}

Advancement in technology is a live example of this concept. Many times, we have encountered strangers entering our campus pretending to be parents and causing us trouble. This happens not only in our university but all over the world, where one person pretends to be others.

In this project report, we are introducing a method to drive away from this problem by maintaining a computerized register for non-authenticated persons like guests or other college students entering the campus. This project is to mainly record the time, details, and purpose of the visit of people entering and leaving the campus. Also, the types included in this system are vast in the market. So, technological advancement is required to combine all such features in a single system. Also, the system should be easily accessible by any beginner or any incoherent person. It also provides security as it's the major requirement from any gate

\author{
${ }^{2}$ Dr. R. Sundararajan, \\ Professor, \\ Dept. of Information Technology, \\ Kalasalingam Academy of Research and Education, \\ Tamil Nadu-626126, India. \\ ${ }^{6} \mathrm{~V}$. Harinidevi, \\ Dept. of Information Technology, \\ Kalasalingam Academy of Research and Education, \\ Tamil Nadu-626126, India.
}

by any user, without security the system is of no use. So, security is also a non-compensable feature of this system.

The main task of this system is to reduce manual work and time of the visitors and bring technological advancement in society.

The person who needs to enter the campus has to get prior permission from the person whom they wish to meet inside the campus by registering their details on our created website, from which the visitor's details are automatically saved on our database. After getting permission, the visitor will get a QR code generated in -his/her mobile which will be scanned by the QR scanner in our gate, and the information is saved in our server. Once the visitor leaves the campus the QR code becomes invalid. For persons coming regularly to college such as parents to drop their wards or vendors cannot get permission every day. To overcome this, they are provided with Radio Frequency Identification ("RFID") tags that are worn or carried by them. The system would then track with the help of an RF reader and the details are stored automatically.

\section{EXISTING SYSTEM}

The existing system for the gate management system on our campus is that they consist of a surveillance camera through which the visitor's entry can be captured by the camera and the security enters the details of the visitors manually in a register. This system has a disadvantage of time consumption and also includes the risk of losing the register by which all the visitors' entries are lost. This isn't a productive way and the reasons are truly straightforward.

\section{PROPOSED SYSTEM}

The proposed system is that the visitor need not wait for the person's arrival. The visitor has to register early to let the person know about their arrival in prior. By this, we can not only save the visitor's time but also can monitor the visitors record.

In this project Admin approves the visitor's request by verifying their information and grants permission to enter the campus. By this way we can monitor the people entering 
and leaving the campus we are using following requirements:

- RFID tag and Reader - Frequently visiting guests and regular visitors on the campus.

- QR code - Quick Response is to reduce Visitors wait for the response from the Staff.

- Messaging and Mailing Service - We have included messaging service in this project once they create a new user id, any changes in their profile or any request they make to visit the person inside the campus, we will send message to their mobile number and alternate mobile number. Also, we make the notification alert to their mail as well.

The Entry Monitoring System will import from the Administrative Data Processing office the approved workforce database as the primary query table.

This new online framework is utilized to characterize the permitted work force approved to permit access via vehicle to visitors. Which implies for each section there is somebody answerable for.

The end client will have made sure about web interface to enter the visitor subtleties with inviter qualifications which will be prepared for legitimacy and upon progress will be available online to the Security workforce possessing the doorpost. Presently framework would have data who is visiting, for what reason for, who has welcomed him.

The greeting will be kept in the database and will be accessible to the Security staff and to the invitees. The administrator can see any record anytime.

Full electronic organization and report were executed dependent on SQL questions. The database has all records and security proportions of records.

\section{A. Abbreviations and Acronyms}

- RFID-Radio Frequency Identification

- QR-Quick Response

- PHP- Hypertext Preprocessor

- MYSQL-My Structured Query Language

- HTML-Hyper Text Markup Language

- CSS-Cascading style sheets

- XAMPP-Cross-Platform Apache MariaDB PHP and Perl.

\section{B. Working}

The working of this project is explained in the flow diagram below. The visitors first need to visit our website http://www.mrstraders.in/KARE-EMS/index.html and register their details for the first time. After this, they can simply log in whenever they want to visit our campus. The registration includes all their details including a photograph and their mobile number. The photo should be uploaded at the time of registration itself. All their details will be stored in our database after a successful registration. After that, they can log into the website whenever they want to visit the campus by requesting approval for their visit for which information like, purpose to visit the campus, the person they wish to visit, the timings and all need to be filled and then a formal request is made to the concerned person. After they verify, they will accept the request which in turn, an OTP is generated to the visitor. At the time of visiting, the visitor needs to scan the OTP in the scanner and all the details already stored in our database get scanned as entry check and now the visitor can enter the campus after the OTP scan is successful. After visiting, the visitor once again needs to scan the OTP which leaves an exit check.

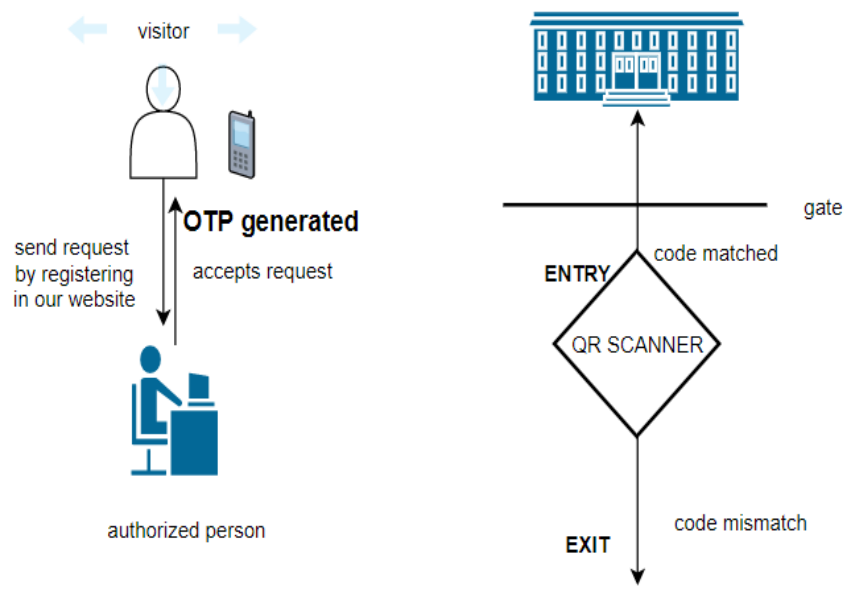

Fig. 1:- Block Diagram of EMS

\section{Explanation}

Entry Monitoring System has been developed on PHP and MYSQL. The main aim of this project is to the manage entry and exit of the visitors. The Entry Monitoring System also allows the employee to manage all incoming and outgoing processes from our campus. The main purpose of this system is to secure the campus from unauthorized persons.

Our project is developed using the below technology

- HTML - page layout has been designed in HTML.

- CSS - CSS has been used for all the design part of this project.

- JavaScript - All the validation task and animations developed by JavaScript.

- PHP - All the business and frontend logic has been implemented in PHP.

- MySQL - To store all the data into the MySQL database.

- XAMPP - We use to run the Website in the Xampp server.

- Apache2: This project will run over the Apache2 Server.

Our project is developed to provide convenience to all visitors. The project is working with the help of 3 important requirements.

\section{QR code Generator:}

In this part, we generate the QR code randomly for the visitor. Visitors after registering the date and time of visiting the campus should wait for the approval from the concerned 
ISSN No:-2456-2165

person. The person verifies and approves their request for visiting the campus. After this QR code is generated to the visitor's page. Before entering into the campus, they must show their QR code in the QR scanner in the Campus Gate. After scanning the QR code all the details will be registered in the monitor. The details include the information of visitors and the person who gave approval to the visitors visiting the campus.

\section{RFID tag and Reader:}

In this part, we use the RFID tag and reader. This system is designed for frequent visitors as they cannot register and wait for permission every single day. They should pay and get the RFID tag. This is the temporary Identity Card for visitors who visit regularly.

\section{Messaging and Mailing Service:}

In this part, we have used google messaging service. This system sends a message automatically to the authorized person inside the campus in the form of pop up notification about the request and their arrival.

\section{RESULTS AND DISCUSSION}

By using this KARE - EMS automation system, an organization has the option of increasing the level of security. This website is very secured, fast, easy to access, and easy to maintain. The resulting web pages of our website is given below. The outcome of our website images is attached below.

\section{$>$ LOGIN PAGE:}

This is the login page of the admin. This page is accessible to everyone.

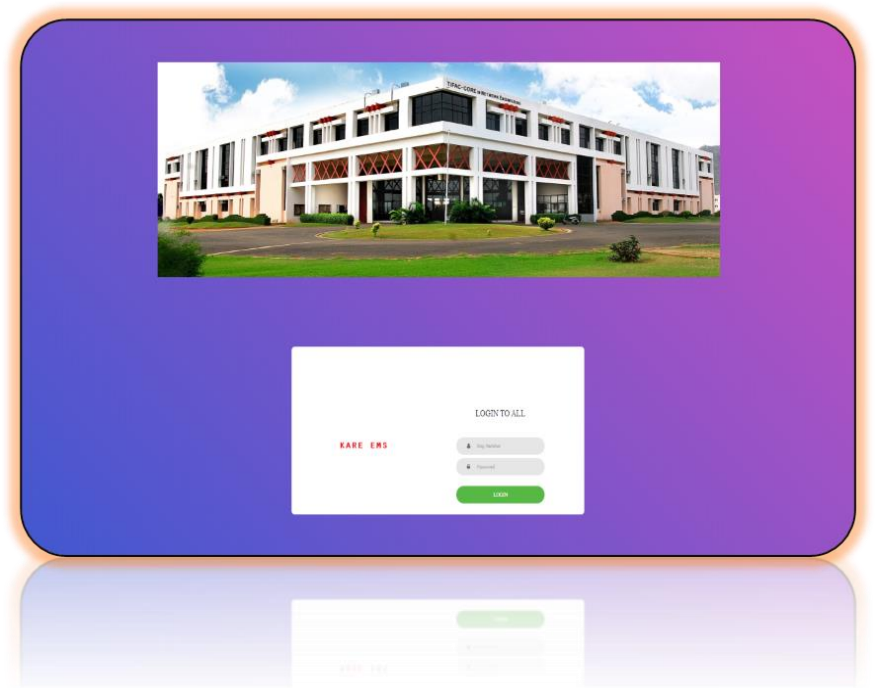

Fig. 2:- Login page

ADMIN PAGE:

After logging in, the admin has to add a student or faculty who has seek request for a visitor to visit them.

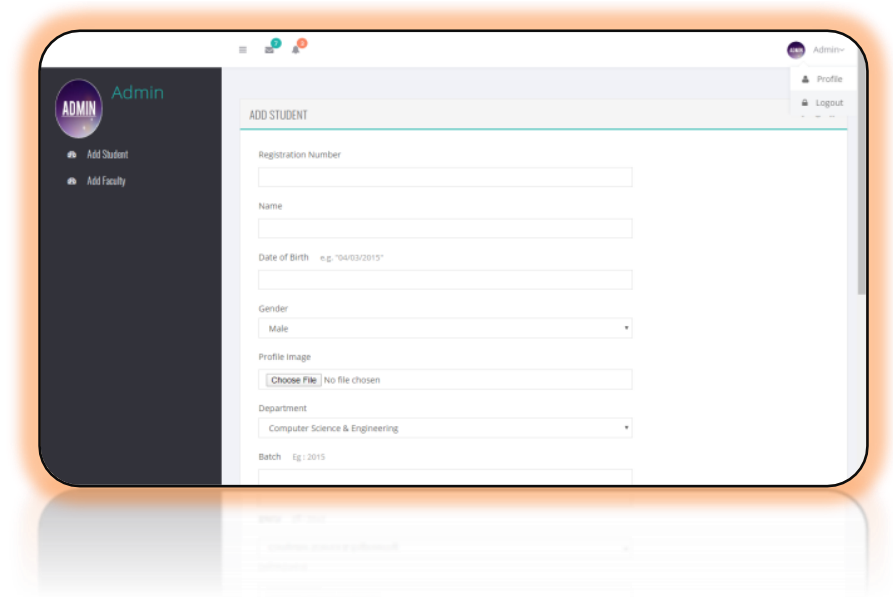

Fig. 3:- Admin page

\section{HOD LOGIN:}

In this page all the requests waiting to be approved will be shown to the HOD after the request is made by the visitor.

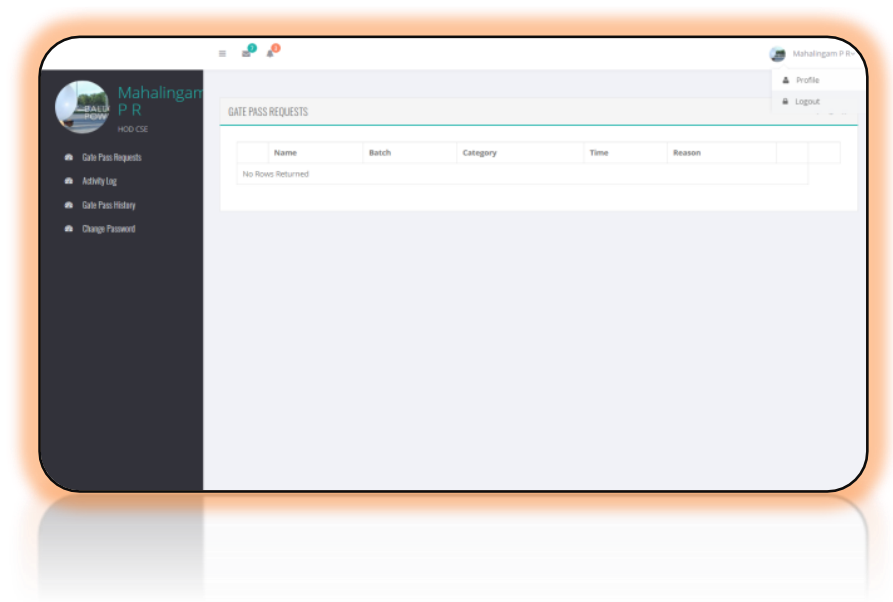

Fig. 4:- HOD Login page

\section{STAFF LOGIN:}

In this page all the requests waiting to be approved will be shown to the respective faculty after the request is made by the visitor.

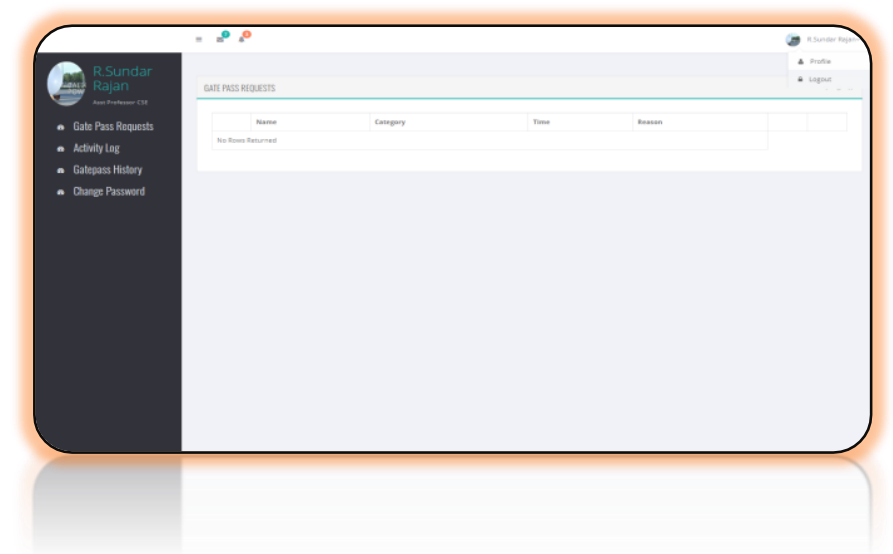

Fig. 5:- Staff Login page 


\section{EMPLOYEE LOGIN:}

In this page all the requests waiting to be approved will be shown to the respective employee faculty after the request is made by the visitor.

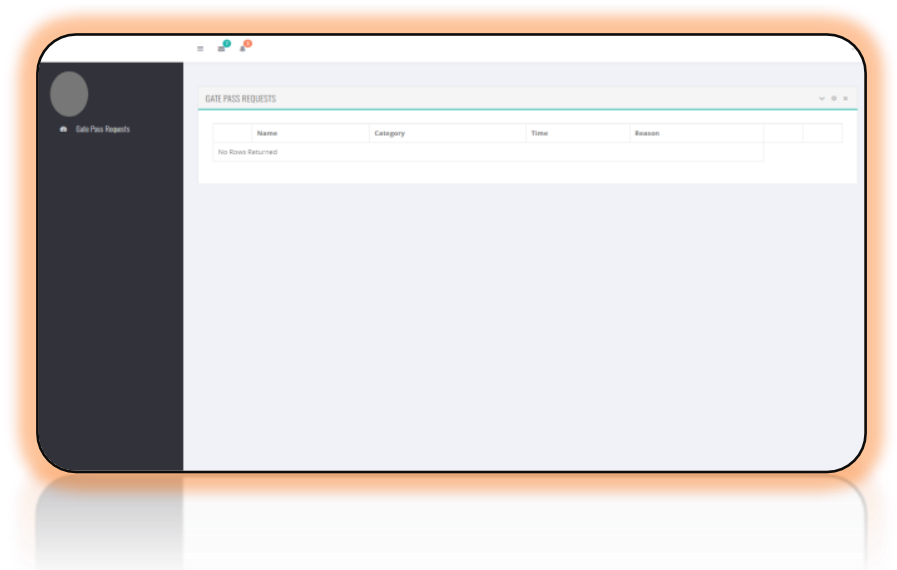

Fig. 6:- Employee Login page

\section{STUDENT LOGIN:}

This page is for students coming from other colleges. Here they are asked reason for their arrival and their details.

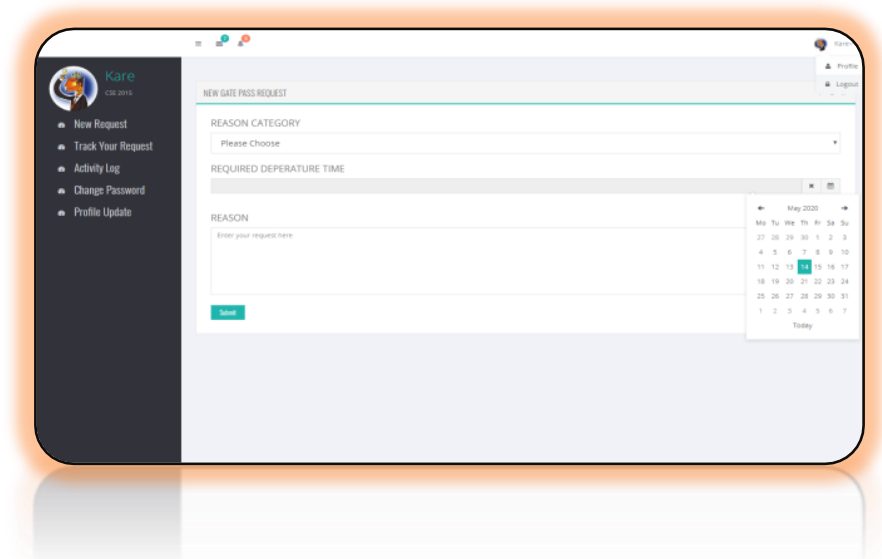

Fig. 7:- Student login page

Once they sent the request, they can track their request status by clicking request tracking.

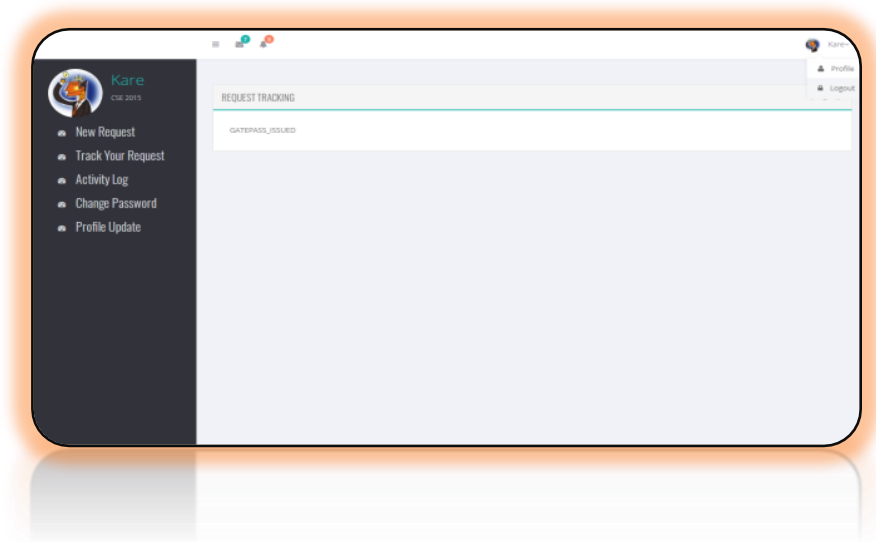

Fig. 8:- Request Tracking page
This is the activity log page of requests received and accepted.

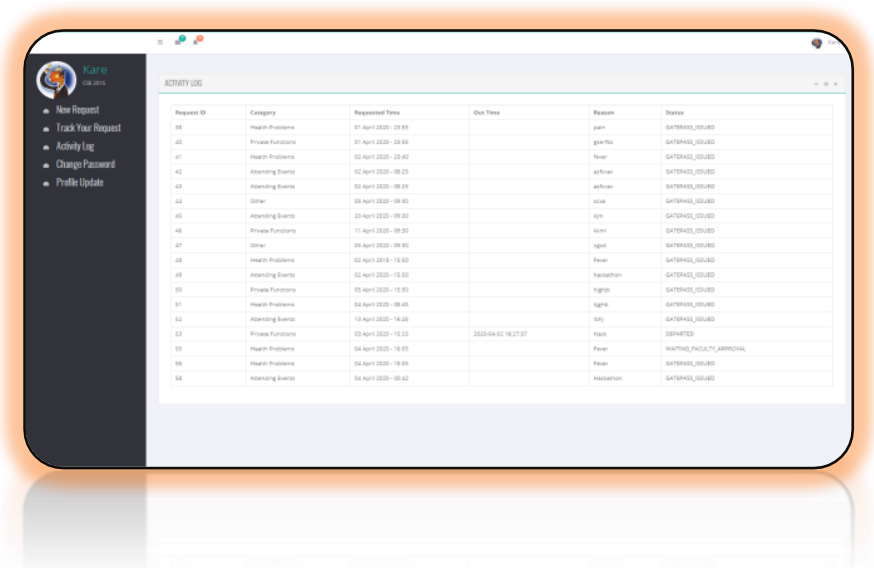

Fig. 9:- Activity Log page

\section{GUARD PAGE:}

This page is for security guard. The activities like scanning QR will be taken place by the help of this page.

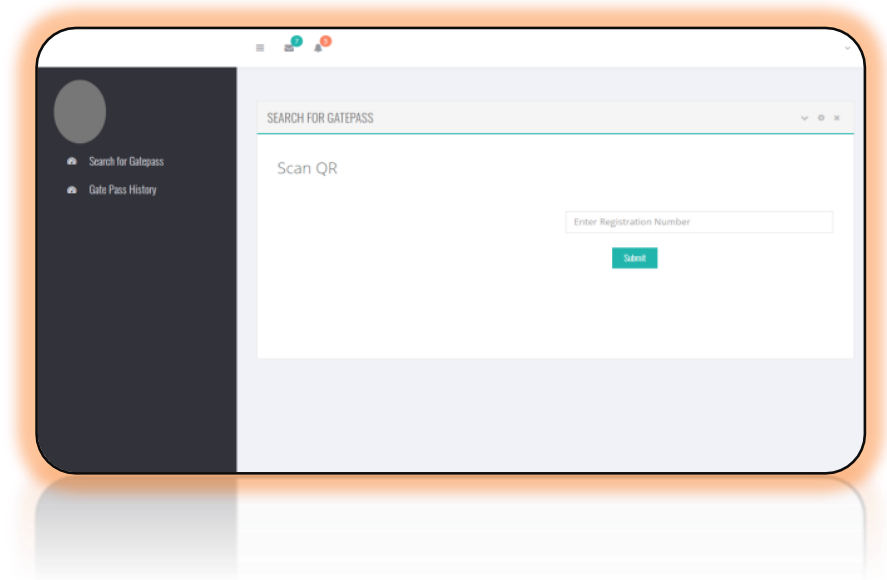

Fig. 10:- Guard page

This is the profile update page in case of any changes needed to made.

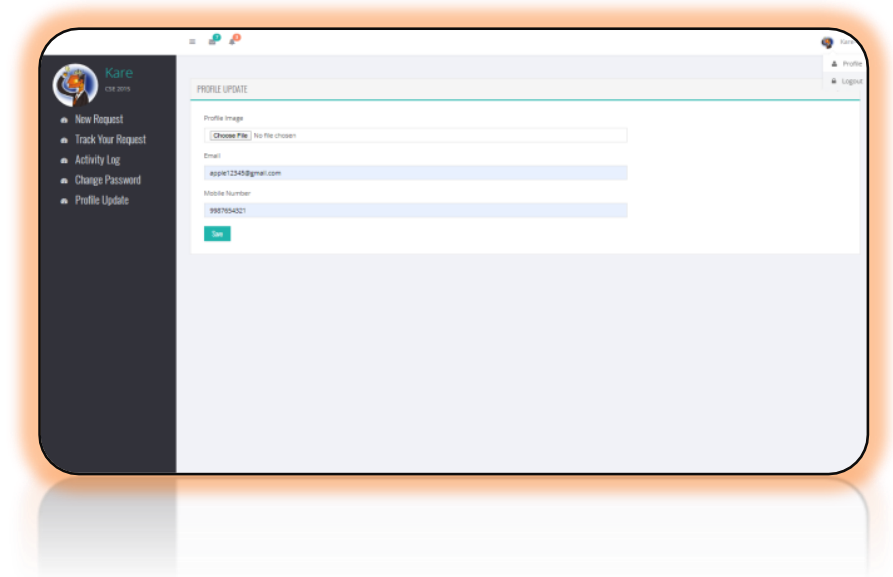

Fig. 11:- Profile update page 


\section{CONCLUSION}

We have successfully designed our website for Entry Monitoring System. This Website is very easy to access. We designed it in secured and simple manner. The proposed work is that the visitor need not wait for the person's arrival. The visitor has to register early to let the person know about their arrival in prior. By this, we can not only save the visitor's time but also can monitor the visitors record. We have also included an RFID tag and reader for people visiting on regular basis.

\section{FUTURE SCOPE}

The most efficient application of our project is in colleges and that is the reason why it was particularly made.

The same thing can be applied in schools and other educational as well as non-educational institutions as well as where there is a requirement of monitoring and maintaining records of people entering and leaving.

Similarly, such kind of system can be implemented in offices where there is no time to monitor the attendance of employees and to monitor the total working hours of the employee by providing an RFID.

\section{REFERENCES}

[1]. A. S. Narayanan, 'Qr codes and security solutions', International Journal of Computer Science and Telecommunications, vol. 3, no. 7, pp. 69-71, 2012.

[2]. Hasib Zunair, Oishi Maniha, Mohammad Jubayer Kabir 'Design and Implementation of an Automated MultiFunctional Attendance System with Real Time Web Visualization', 2018 2nd International Conference on Smart Sensors and Application.

[3]. Nusrath Jahan, Kamal Hossen, Muhammad Kamrul Hossain Patwary, 'Implementation of a vehicle tracking system using smartphone and SMS service', 24th International Conference on Advances in Electrical Engineering, IEEE Xplore Digital Library, 2018.

[4]. I. Kapsalis, 'Security of QR codes', Norwegian University of Science and Technology, Master in Security and Mobile Computing 2013G. Eason, B. Noble, and I.N. Sneddon, "On certain integrals of Lipschitz-Hankel type involving products of Bessel functions," Phil. Trans. Roy. Soc. London, vol. A247, pp. 529-551, April 1955. (references)

[5]. Leon Atkinson, 'PHP Core Programming', Beijing: Tsinghua university press, 2000.

[6]. Seinivas Nidhra, Likith Poovanna, Vinay Sudha Eithiraj, (2012), Visitor Management Schedule SystemAn Intelligent Decision Support System, School of Computing, Blekinge Tekniska Hgskola, Karlskrona, Sweden.

[7]. HaiyaHamood Al Ghaithi, Umapathy Eaganathan, (2016), A BRIEF STUDY AND IMPLEMENTATION OF VISITOR MANAGEMENT SYSTEM FOR ASIA PACIFIC UNIVERSITY, MALAYSIA 